\title{
Transthoracic Echocardiographic Assessment of Proximal Coronary Arteries
} \author{
Swetha Srialluri ${ }^{1}$ \\ ${ }^{1}$ Division of Cardiovascular Disease, University of Alabama at \\ Birmingham, Birmingham, Alabama, United States \\ J Card Crit Care TSS 2017;1:34. \\ The patient is a 55 -year-old woman status post two mitral clips \\ with a severely dilated left atrium and persistent severe mitral \\ regurgitation. During a follow-up, an attempt was made to \\ examine the proximal coronary arteries by two-dimensional \\ transthoracic echocardiography ${ }^{1-3}(-$ Videos $1-4)$.
}

Omar Tageldin ${ }^{1}$ Navin C. Nanda ${ }^{1}$ Mohammed J. Arisha ${ }^{1}$ Ahmed Abdelhaleem ${ }^{1}$ Ayman Battisha ${ }^{1}$

\section{Videos 1-4 \\ The left main (LMC), proximal left anterior descending (LAD), and left circumflex (CX) coronary arteries are well seen in B-mode (-Videos 1,2 ) and with color Doppler (-Video 3). No significant stenosis is noted in the visualized vessels in B-mode. Color Doppler signals are also laminar with no flow aliasing or turbulence consistent with no obstruction. - Video 4 shows normal right coronary artery (RCA) orifice viewed using the right parasternal examination approach in}

Address for correspondence Navin C. Nanda, MD, Heart Station/ Echocardiography Laboratories, University of Alabama at Birmingham, Spain Wallace Building, S102, 619 19th Street South, Birmingham, AL 35249 (e-mail: nanda@uab.edu).

the same patient. AO, aorta; LA, left atrium; PR, pulmonary regurgitation; PV, pulmonary valve; RAA, right atrial appendage. Online content including video sequences viewable at: www.thieme-connect.com/ ejournals/html/doi/10.1055/s-0037-1604211.

\section{References}

1 Nanda NC, Sungur A, Bhagatwala K, Karia NM, Oz TK. Non-standard echocardiographic examination. In: Nanda NC, ed. Comprehensive Textbook of Echocardiography. New Delhi, India: Jaypee Brothers Medical Publishers; 2014:188-223

2 Vengala S, Nanda NC, Agrawal G, et al. Live three-dimensional transthoracic echocardiographic assessment of coronary arteries. Echocardiography 2003;20(08):751-754

3 Whitfield T, Farag AA, Nanda NC. Direct visualization of coronary arteries and coronary blood flow. In: Ravi Kasliwal, ed. Applied Echocardiography in Coronary Artery Disease. New Delhi, India: Jaypee Brothers Medical Publishers; 2016:181-209
DOI https://doi.org/ $10.1055 / \mathrm{s}-0037-1604211$
Copyright @ 2017 Official Publication of License terms The Simulation Society (TSS), accredited by International Society of Cardiovascular Ultrasound (ISCU) 